\title{
Exploring the Adult Learning Research Field by Analysing Who Cites Whom
}

\author{
Erik Nylander ${ }^{1}$ (D) Lovisa Österlund ${ }^{2}$. \\ Andreas Fejes ${ }^{1}$
}

Received: 20 September 2016 / Accepted: 3 May 2017 /

Published online: 31 May 2017

(C) The Author(s) 2017. This article is an open access publication

\begin{abstract}
In this article we report on findings from a large-scale bibliographic study conducted based on the citation practices within the field of research on adult learning. Our data consist of 151,261 citation links between more than 33,000 different authors whose papers were published in five leading international journals in the field of adult learning during the time period 2006-2014. By analysing the composition of the dominating citation clusters we are able to construct a telescopic view of the research field based on an accumulation of bibliographic citations. The results consist of two parts. First we go through the dominating players active in the field, their position and mutual relationship. Secondly, we derive two main structural oppositions inherent in the citation networks, one connected to the research object (studying education or work) and the second to the level of analysis (cognition or policy). We find that the most dominating tradition within adult learning the last few decades - sociocultural perspectives on learning - occupies a very central position in the space of citations, balancing between these opposing poles. We hope that this analysis will help foster reflexivity concerning our own research practices, and will reveal the relations of dominance currently prevailing within the field of adult learning.
\end{abstract}

Keywords Bibliometrics $\cdot$ Scientometrics $\cdot$ Adult education $\cdot$ Workplace learning $\cdot$ Field analysis · Bibliographic research

Electronic supplementary material The online version of this article (doi:10.1007/s12186-017-9181-z) contains supplementary material, which is available to authorized users.

Erik Nylander

erik.nylander@liu.se

1 Department of Behavioural Sciences and Learning (IBL), Linköping University, Linköping, Sweden

2 University Library, Linköping University, Linköping, Sweden 


\section{Introduction}

In recent years, researchers throughout the world have come under increased pressure to publish in English, direct their scholarly work to internationally acclaimed journals indexed in the dominating databases (i.e. Scopus and Web of Science), and render their work citable among peers in other countries. Strong political waves of managerial reforms are gradually making academic career trajectories and promotions more dependent upon what Larsson (2009) calls "an emerging economy of publication and citations". This development, as well as the standardized measurements of scientific output and evaluation on which it is reliant (number of articles, journal impact, average citations, etc.), is often criticized for giving highly inadequate or reductive images of the complex ways scholars in diverse fields relate to the question of quality (Karpik 2011; Gingras 2016).

The establishment of "what counts" as quality among scientific peers is arguably a rather opaque issue, where the valuation practices of different research fields are divergent from one another (cf. Lariviére et al. 2006; Hicks 2004; Gingras 2016; Lamont 2009). It has also been pointed out that the kind of ranking and benchmarking procedures which are often established to evaluate research, tend to trigger re-activation strategies among researchers as well as institutions as they try to maximize their own remuneration and climb collegial "pecking orders" (Espeland and Sauder 2007; Carruthers and Espeland 1991). Although contemporary forms of political steering have placed much weight on bibliographic data and scientometric analyses, these tools are still rather under-utilized for making more detailed accounts of the modus operandi of distinct research fields and for mapping out their scientific content and dominating players.

In this paper, we will map out the position of the dominating research traditions within the field of adult learning by use of a bibliographic cartography. Our empirical material consists of a relational database of cited work in articles published between the years of 2006 and 2014 in five peer-reviewed journals pertaining to adult learning listed in Scopus: Adult Education Quarterly, International Journal of Lifelong Education, Studies in Continuing Education, Journal of Education and Work and Journal of Workplace Learning. Our sample thus includes all references in the reference list of articles and reviews published in these five journals over a period of eight years, in total 151,261 citation links between more than 33,000 different authors.

Drawing on the tradition of the sociology of science known as field analysis (Bourdieu 1988) we identify the dominating players based on the total number of citations, outline their positions in relation to one another and unravel the main epistemic traditions present in the field. Although we do not think that the total number of citations can be taken as a proxy for research quality, we believe that the bibliographic method we outline has a series of distinct advantages in comparison to conventional bibliometrics analysis (Hicks 2004, 2013; Persson 1991; Lariviére et al. 2006) as well as previous bibliometrics studies on the field of adult learning (Fejes and Nylander 2015; Rubenson and Elfert 2015; Käpplinger 2015; Larsson 2010; Taylor 2001). Firstly, we are able to give a synthetic and panoramic view of the research field of adult learning based on previous citation patterns by utilizing the power of big data, spanning 
in total 151,261 citation links between more than 33,000 different authors. Secondly, our account takes into consideration the total sum of bibliographic citations and is not limited to articles, as is often the case in more conventional bibliometric methods. Thirdly, we are able to distinguish between standard references directed towards bibliographies belonging to researchers active within the field, and references to those who are highly cited but do not engage in the field yet who are part of the positional struggle. Finally, we point to two main structural oppositions pertinent within this subfield, one connected to the research object (Education versus Work) and one that separates scholars based on the level of analysis (Cognition versus Policy). The overall aim of this exercise is to unravel the relationship between the dominating scholars in the field and thereby to foster what Bourdieu calls "epistemic reflexivity", i.e. a better understanding of the theoretical perspectives within which research is conducted and the various positions scholars engaged in the field can potentially uptake (Bourdieu and Wacquant 1992, 40-41).

\section{Governed by Peers}

One of the fundamental traits of scientific practice since it established institutional autonomy is that the value of any given knowledge contribution is decided upon collegially among peers (Bourdieu 1988; Bourdieu and Wacquant 1992). Even if the relative autonomy of research varies over time as well as between different disciplines, most research fields are organized in ways that make corruption, nepotism and direct manipulation of knowledge difficult. One important instrument to safeguard the relative independence of research is the collegial process of peer review taking place before final publication and to ensure the legitimacy of appointments. The peer review system should, ideally at least, help protect research from the influence of external interests and pressure, as well as tendentious and flawed argumentation. Peer reviewing of articles can, at its best, help to refine the quality of the research as initiated and knowledgeable colleagues are provided with the opportunity to validate findings and provide critical feedback. At the same time, it is also the role of peer reviewers to determine what should pass as knowledge in the first place, as opposed to personal opinions, common-sense or wishful thinking. However, due to the anonymity criterion of peer reviewing these assessments are arguably marked by a kind of pseudo-neutrality where the position of the peer-reviewer tends to remain concealed throughout the evaluation processes. This intangible judgement processes of ongoing research can be quite frustrating for individual scholars who, at some point throughout their careers, will think that their work has been neglected, misconceived or illegitimately criticized.

Another difficulty with this rather opaque system of collegial valuation is that it makes it hard to get a panoramic overview of all the different researchers active in judging and evaluating what should count as knowledge, their positions in relation to one another and their accumulation of academic credentials over time. One way to analyse the formation of knowledge production in an entire research field is to gather 
bibliographic information from databases such as Web of Science (WoS) or Scopus. Even though we should acknowledge that bibliometric and bibliographic data is far from exhaustive and that the collegial recognition of peer-reviewed articles differs greatly between scientific disciplines, across countries and over time (Hicks 2013; Lariviére et al. 2006), we think that citations in indexed peer-reviewed journals still count among the basic signs of collegial recognition. Furthermore, by using bibliometric measurements, drawing on large-scale databases, it is possible to analyse citation patterns within different sub-fields in the social sciences as well as to span a great number of publications.

One of the major problems with using conventional bibliometric measurements within research fields of the social sciences and humanities, is that the culture of referencing within these research branches differs greatly from, say, natural science or medicine (Lariviére et al. 2006; Gingras 2016). For instance, references in the social sciences are often made to other forms of publications than articles; something that is rarely accounted for in standard versions of bibliometrics. If one does not take into account knowledge contributions made available in other publication formats than articles, one risks excluding theoretical and methodological inspirations available in the format of books, as well as contributions made available in other forums for societal debate, philosophy etc., all of which have been proven to be of particular importance to many of the research fields pertaining to the social sciences and the humanities (Hicks 2013; Lariviére et al. 2006). When one, as in our case, takes a specific research field as the object of enquiry, one should therefore, besides more conventional analysis of articles and citations, also try to include analysis of "impact" of other forms of publication such as books, book chapters, and texts written for a wider audience, in terms of the formation of the specific research fields as well as citation practices. For instance, conducting bibliometric research within the educational sciences makes referencing to didactical and pedagogical literature paramount - publications that sometimes but certainly not always come in the form of peer-reviewed articles.

\section{Previous Research}

This study connects with earlier research in three different domains. Firstly, it connects with the sociological tradition of Bourdieu and, more specifically, the analytic model of exploring knowledge production relationally. Secondly, it seeks to contribute to methodological developments in bibliometric research, especially so in constructing largescale bibliographic images of connections between scholars and between epsietemological research traditions. Lastly, it adds to our understanding of the present day shape and composition of the research field on adult learning. Before presenting the details around our study, a brief note on some of the previous research conducted in each of these three domains is necessary.

Aside from Bourdieu's work on science (1988; 2004), numerous scholars have used the concept and methodological insight of studying fields in order to analyse and better understand knowledge production. Such work includes that of Heilbron (2015) who recently focused on the emergence and transformation of French sociology, or Broady's (1991) work that dealt with the reception of Bourdieu's sociology throughout the Western world by means of a bibliometric analysis. One of the traits of this research 
tradition is the aim of unravelling the structural oppositions inherent in any scientific field and interpreting the position and weight of distinct scholars or traditions relationally; that is to say in relation to the position one another. From Bourdieu's own work on "the science of science" (2004), we know that social science at large holds a rather ambiguous position in the academic landscapes to begin with, on the one hand not really at home within the humanities faculties (philosophy, history, language), yet on the other hand far from the exact sciences of natural science or medicine.

There have also been some previous bibliometrical studies analysing publication and citation patterns within the field of adult learning more specifically. These have mainly focused on identifying issues pertaining to who is publishing in terms of geography, gender, as well as in terms of academic position, and what kind of research is being published in terms of content, such as the object of research, theory, and method. Some of these studies focus on a single journal only and its development over time (e.g. Harris and Morrison 2011; St.Clair 2011; Taylor 2001), while others focus on identifying issues of authorship and content across several journals (Fejes and Nylander 2014; Larsson 2009, 2010; Rubenson and Elfert 2015) and yet some focus on conference publications (Käpplinger 2015). In short, these studies identify the following characteristics of adult learning as a research field: authors located at universities in the UK, US, Australia or Canada dominate the field in contribution as well as collegial impact; female authors render more publications than men do, while male authors still dominate the field in terms of scientific recognition and impact (Fejes and Nylander 2015; Taylor 2001). Methodologically, research tends to be conducted within the qualitative paradigm, with interviews, sometimes in combination with observations, as the main method of generating data (Fejes and Nylander 2015; Käpplinger 2015). Theoretically, sociocultural perspectives on learning dominate and topic-wise, adult learning has been found to be the most common thematic (Fejes and Nylander 2015; Rubenson and Elfert 2015).

The above studies provide valuable insights into how the field of adult learning research is being shaped. However, what is lacking is an analysis of the field in terms of its emergence based on who is being recognized by peers through the practice of citation. Even though Larsson (2009) and Fejes and Nylander (2015) draw on citation data in their analyses, their data sources has either been very limited in size (Larsson 2009), or mainly focusing the issue of geography of authorship and institutional affiliation (Fejes and Nylander 2014, 2017). Thus, this article will contribute a more all-encompassing analysis of how the field of adult learning emerges through citations, and of the position that dominating traditions and scholars have within it.

\section{To Understand Research through Citations: Theory and Method}

As indicated earlier, this paper draws inspiration from a research tradition within the sociology of science that map out the structures of any given research field relationally (Bourdieu 1988) as well as explorative methods in bibliometrics (Gingras 2016; Bastian et al. 2009). Building on Bourdieu's work we conceive a research field as a relationally structured space with its own rules of entry and within which agents compete about scientific recognition (Bourdieu 1988; Sapiro 2010). Arguably, symbolic forms of recognition is particularly pertinent within social fields that has 
established a certain degree of autonomy to the surrounding world, such as a scientific field of academics or the cultural field of jazz musicians (Nylander 2014a, b). ${ }^{1}$ Even though much of the political usage of bibliometric measurement has gone awry, citations still hold as an important sign of collegial recognition that can be explored empirically. Bibliometrical measurement is especially useful for exploring bibliographic links and research networks, what the bibliometrican Yves Gingras calls "descriptive cartographies" (Gingras 2016, 75).

The number of citations and citations links obtained by other colleagues is obviously just one of many possible signs of such scholarly recognition, although it is a measurement that has come to be more salient in research policy in the last few decades, following largely on a series of managerial reforms (cf. King 1987; Larsson 2009; Gingras 2014). Yet, instead of a critical denunciation of the politics that led to the efforts to reduce scientific excellence to standardized evaluation measurements, our aim with this text is to use the bibliographic data made available to us though acclaimed databases, to understand relations among the researchers dominating the research field. More particularly, we will seek to demonstrate what kinds of epistemological objects, academic traditions and research themes have been cited and have thus acquired a dominating position in the research field on adult learning in recent years. Although a much debated issue we assume that adult learning can be seen as an academic field in its own right within which symbolic forms of recognition are simultaneously sought after and agreed upon through research practices (Bourdieu 1985, 2004; Bourdieu and Wacquant 1992). ${ }^{2}$ Our first research question concerns whom in the field is attributed scholarly value based on the number of citations, and what position he or she occupies in the space of citations. The second research question focuses more on the structural opposition that permeates this particular research field, i.e. regardless of what individual bibliographies happen to embody the most central positions. Since our aim here is to provide a birds-eye view of the research field through recent citations practices, we will have to leave aside bigger questions of the historical emergence of adult educational research as such as well as its political legitimacy.

\section{Method, Data and Analysis}

We have selected five journals in the broader adult learning field for further analysis. These were selected, firstly, based on the journals representing different areas of research within the wider field of adult learning; adult education, continuing education, lifelong education, and workplace learning. Secondly, the journals were selected based on a criterion of publishing within the field for a longer period of time. ${ }^{3}$ Thirdly, we sought to construct a sample of journals where the editorial work was carried out in different geographical locations and distributed by different scholarly publishers. All the selected journals has also acquired an indexation status in Scopus, and is thus

\footnotetext{
${ }^{1}$ However, Broady (1991) argues that symbolic capital can be seen as the most generic concept in Bourdieu's toolbox, one that permeates to the three forms of capital his work is normally associated with, i.e. cultural, social, and economic capital.

${ }^{2}$ For other discussions on the status of adult learnig as a research field see e.g. Bright (1989), Larsson (2010); Rubenson and Elfert (2015), Fejes and Nylander (2017).

${ }^{3}$ Thus, other newer journals such as, e.g. Vocations and Learning, or The European journal for research on the education and learning of adults, were not part of our sample.
} 
categorised as "international" in contexts where an international publication is encouraged through different methods of measuring quality. The reason for not selecting journals indexed in WoS is that only a very few journals in the adult learning field were indexed there at the time of our enquiry. The five selected journals from Scopus thus provide a wider empirical basis for comparison and analysis. The five journals selected were:

- Adult Education Quarterly (Published in the USA)

- International Journal of Lifelong Education (Published in the UK)

- Journal of Education and Work ${ }^{4}$ (Published in the UK)

- Journal of Workplace Learning (Published in the USA)

- Studies in Continuing Education (Published in Australia)

The empirical sample from these journals includes all articles and reviews published between 2006 and 2014, in total 1219 publications. Other document types than articles or reviews often do not include reference lists in Scopus and was therefore excluded.

Rather than only focusing on who are publishing as well as being cited most, we chose to analyse the relationships between different actors in the field based on direct citation relations, i.e. to analyse who cited whom. We started to create the database by downloading all 1219 articles and reviews from Scopus as a csv file. To generate the citation links between the citing and cited authors a Visual Basic script was written to separate authors in the author column and the authors from individual references in the reference column. This was done based on last name and initials. ${ }^{5}$ While the author column was rather easily isolated, the reference column often contained both author and editor names which required further identification procedures. After running the script, a manual extraction of author names from the reference column was carried out. Names of organizations and government authorities were ignored since the focus of the study is on individual authors, traditions and field positions. Furthermore, all variants of citing and cited author names were gathered for a manual cleaning process. Of the 33,932 names, 862 name variants were identified and corrected among the most frequently occurring names. ${ }^{6}$ The corrections were replaced in the direct citation links.

Individual self-citations were also excluded, though citations from co-authors of previous works were still counted. In order to avoid the pitfall of portraying authors with inflated citation figures by having been cited by publications having multiple authors a fractionalization approach was used based on the number of citing authors. However, fractionalization based on the number of cited authors was not used, meaning that a cited author would get as much credit for being a single author as for being part of a group of authors. The main reason for not fractionalizing the cited authors here has been our empirical focus on the relationship among scholars currently active in the field. If the chief focus would have been on citation counting as such this method might

\footnotetext{
${ }^{4}$ This journal publishes papers which concerns adults learning as well as the learning of youths in the regular school system. Since the journal is one important publication outlet for adult learning scholars interested in relations between education and work it was included in our sample even though it has a slightly wider scope. ${ }^{5}$ Please note that Scopus includes a maximum of eight authors per reference - the seven first ones and the last. In the field of adult learning this is a minor limitation as few publications contains more than eight authors. ${ }^{6}$ All author subjects with more than ten citations and the 100 most cited authors were double checked by two researchers independently.
} 
seem problematic as it boosts the weight given to actors with a track record of numerous well-cited co-authored publications. However, as our interest concern the relational position of the most cited scholars and the main epistemological traditions they work within this fractionalization approach and bibliographical method seem less hazardous. ${ }^{7}$

For the creation of the collective map of citations the visualization tool Gephi was utilized (Bastian et al. 2009). ${ }^{8}$ The script generated two network files: a node file and an edge file. The node file contained all citing and cited authors. The edge file contained the direct citation links, edges, between the nodes (authors). To generate the weight of each edge all citation links from one author to another were added up. We also added some additional information to the node files about the authors' current positions on editorial/advisory boards for the journals, before import to Gephi. This supplementary information did not affect the creation of the field positions, but has been helpful in the interpretation and analysis.

Although we claim that this approach is useful for exploring bibliographic cartographies based on citations it also have some limitations. First of all we rely entirely on one type of publication outlet (journal articles and reviews) from a fairly limited time period (2006-2014) in order to construct the space of citations. If other journals would be included in our sample, if we included a longer time horizon or other forms of publications was added on to the citation data base, we do believe that our results could be somewhat altered. Another possible limitation has to do with the way we chose to fractionalize or give weight to the different bibliographical entries. By equalizing citation weight given to individual and multiple authorship, we can potentially help exaggerate the perceived importance of the most productive and most collaborative scholars in the field. One last limitation worth considering has to do with the rather narrow empirical focus on five journals within adult education and workplace learning. As some leading researchers in the field contribute and give priority to all-together different publications - may this be in rivalling academic fields with more scientific status or other publication venues or languages - our map can be accused of bringing forth scholars more limited in focus, contributing specifically to the relatively small subfield of adult learning.

\section{The Space of Citations: a Telescopic and Bibliographic View}

In the following, we introduce our results by presenting a figure including citations from all five journals. Each individual node in the full space of citations is representing one author, and a line between nodes illustrates citations in the direction of the arrow. The thickness of the line illustrates the number of citations between authors, and the size of the node, as well as the size of the font, illustrates the total number of citations for the specific bibliography regardless of whether books, articles or conference papers are being cited. The location and centrality of the authors in the figure, relative to each

\footnotetext{
${ }^{7}$ A scientometric alternative used to analyse the relation between researchers is co-citation analysis (cf. Small 1973; Persson 1991; Åström et al. 2009).

${ }^{8}$ The networks were visualized in 2D using the ForceAtlas2 algorithm, which is a force-directed algorithm. For more on Gephi see Bastian et al. (2009).
} 
other, thus reflects the overall citation patterns. Authors who are often cited together or who often cite the same author(s) tend to be placed more closely together.

We have filtered out the dominating players in order to make the structure of the field comprehensible. ${ }^{9}$ The filtering is based on the total number of incoming citations to each author, and thus excludes a great number of less cited scholars in greater proximity to each name. The figure therefore zooms in on the central players in the field, measured based on the number of citations (Appendix) and the connections between these agents (Fig. 1).

Figure 1 illustrates the entire research field on adult learning based on citations in the five journals. Several central sub-clusters of authorship nodes can be observed. The most central, and arguably the strongest, cluster is created by the citation bibliographies in the sociocultural theoretical traditions, focusing particularly on learning in work life. Authors such as Etienne Wenger, Jean Lave, Stephen Billett, Yrjö Engeström, David Boud and Phil Hodkinson, represent key bibliographies in this citation cluster (see also Appendix). It is worth noting that two of these citation bibliographies, that of Wenger and that of Lave, do not themselves contribute to the building of the field by publishing in the selected journals, even though they occupy such central positions. Instead these names represent "standard" references called upon as external authorities by researchers contributing to these particular journals. Furthermore, authors representing the most central positions in this cluster are situated in anglophone countries such as USA (Lave, Wenger), the UK (Hodkinson) and Australia (Billett, Boud). Engeström's citation bibliography, although currently situated in Finland, could also be seen as anglophone due to the fact that his career trajectory has involved long-term employment at a North American university.

Another central network of scholars in the field, clearly connected to the one above through citation practices, is found among the bibliographies of authors located in the UK, such as Tara Fenwick, Lorna Unwin and Alison Fuller. This group all engage in research into relations between education and work life (professional education, vocational education etc.). Fuller and Unwin are linked further with colleagues at their own institution (The Institute of Education in London $)^{10}$ such as Karen Evans, Michael Young and Stephen Ball, while Fenwick, whose bibliography is even more centrally located, connects to several scholars who are working at the same institution as her (University of Stirling), such as Richard Edwards, John Field, and Gert Biesta. The centrality of Fenwicks bibliography has to do with the transnational linkages to the sociocultural cluster, a sociomaterial cluster as well as to a North American cluster in the top left of the figure. The latter could possibly be explained by her former employment at universities in Canada.

More generally it is interesting to note how these mainly European/Australian clusters have a rather weak scholarly connection to North American researchers, whom in this field seem to operate pretty much in isolation from the rest. However, two North American clusters of citation bibliographies are visible at the top of the figure, although they seem surprisingly peripheral, especially compared to the sociocultural cluster. In the northwest corner, there are citation bibliographies of Jack Mezirow, Sharan Merriam, Stephen

\footnotetext{
${ }_{9}^{9}$ After generating the network the most cited authors were filtered out. A cut-off rate of 50 fractionalized citations was chosen as the best alternative for level of detail versus readability. For a more "substantialist" view of the bibliographic data of the fifty top-cited authors see table in the Appendix.

${ }^{10}$ One researcher that is absent from the list of top fifty leading citation bibliographies between 2006 and 2014 (Appendix), but nevertheless seem influential in giving shape to the bibliographies in the more sociologically oriented part of the map, is former IOE Professor Basil Bernstein (1924-2000).
} 


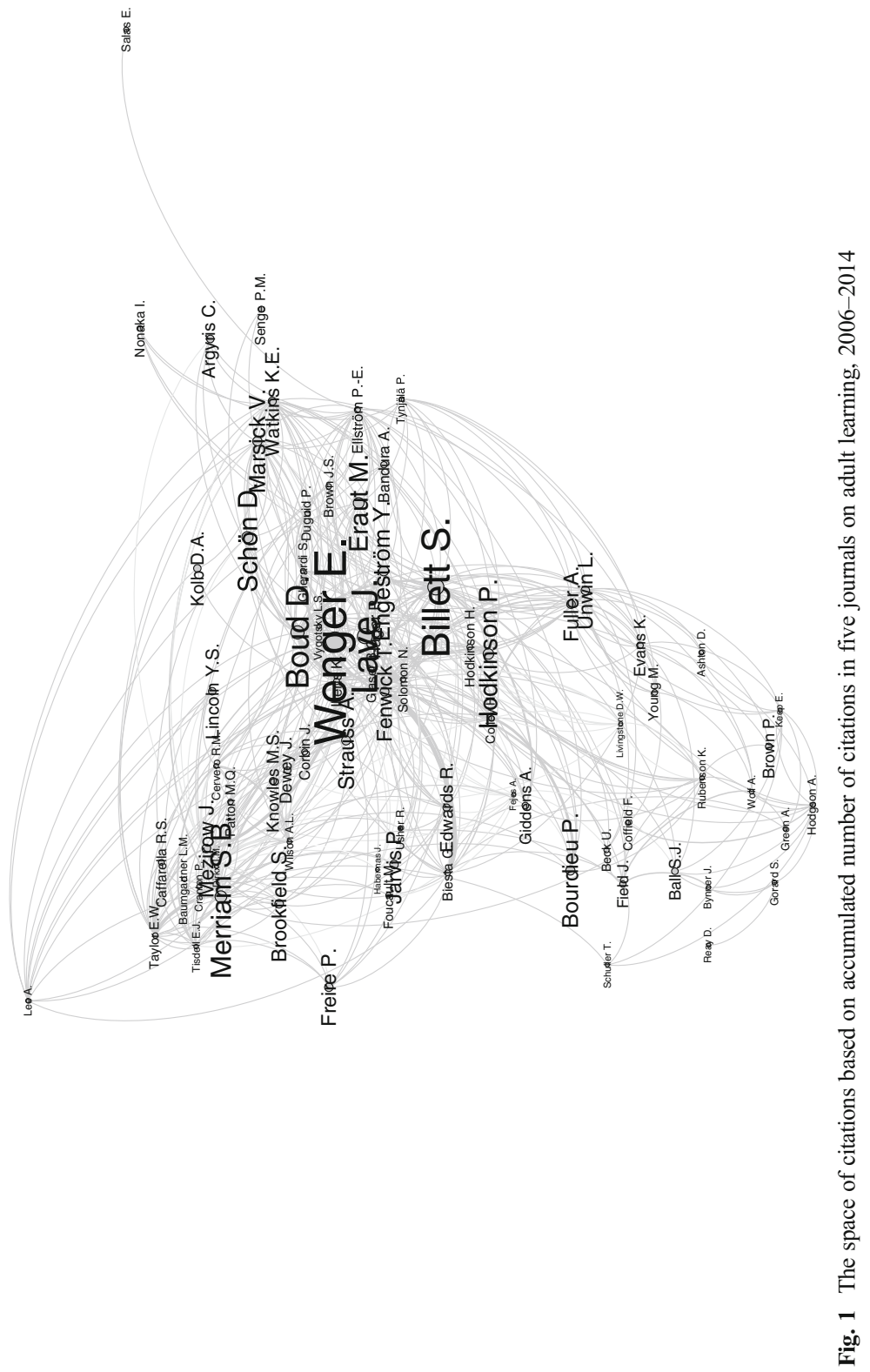


Brookfield, and Edward Taylor, all of whom are located in the US. The connections between their bibliographies create two interrelated subgroups, one where transformative learning theory is central (Mezirow and Taylor), and one where critical pedagogy with a Marxist orientation is central (Brookfield and Freire). ${ }^{11}$ A second North American cluster is visible in the northeast corner. Here, we find citation bibliographies of Karen E. Marsick and Victoria Watkins, illustrating a cluster more oriented towards organizational and management issues. The citation patterns of this group connect up with those of Chris Argyris as well as the Swedish scholar Per-Erik Ellström. In the same space of citations we find some key references to "classics" such as Donald Schön and David Kolb.

West/southwest in the space of citations we find an aggregation of more philosophically and sociologically oriented scholars. One of these clusters consists of bibliographies of authors who are working with poststructural theories such as Richard Edwards (UK), Robin Usher (Australia), and Gert Biesta (UK). In conjunction with these citation bibliographies we find another external reference considered key among some colleagues in the field, that of Michel Foucault (France). In the southwest corner we find another cluster of bibliographies where John Fields (UK) name appear to be central. The more critical sociological tradition is also given weight by external references to seminal work from Pierre Bourdieu (France) as well as Ulrich Beck (Germany). If scholars working in the US tend to dominate the northern side of the space of citations, the southern areas predominantly consists of scholars affiliated to institutions in the UK, with Australian scholars and some scholars that has worked at both sides of the Atlantic (e.g. Fenwick, Engeström), mediating between the two.

Though it is well beyond the scope of our article to investigate what has brought these bibliographies to the centre of the citation practices in research on adult learning, we note that many of these authors currently hold, or have held, positions as editors and advisories to the examined journals. The editorial positions often seem to have a direct link to the field of adult learning, such as for Stephen Billett who currently operates as the editor of Vocations and Learning; David Boud and Nicky Solomon, currently editing Studies in Continuing Education; Edward Taylor, Patricia Cranton, Elisabeth Tisdell, Sharan Merriam, Ronald Cervero, and Arthur Wilson previously editors for Adult Education Quarterly; Phil Hodkinson, currently editor for Journal of Education and Work; Peter Jarvis, previously editor for International journal of Lifelong Education; Alison Fuller, current editor and Lorna Unwin, former editor for the Journal of vocational education and training; and Richard Edwards, previously editor for Studies in the Education of Adults.

So far, we have described our results from the descriptive cartographic exploration. In the next section, we will turn to our interpretation of these results.

\section{Moving across the Field}

If we read Fig. 1 as a map of the research field, we can see how movements from west to east, as well as from south to north provide interesting analytical and epistemological structures. Our interpretation of this map is presented in Fig. 2 below.

\footnotetext{
${ }^{11}$ The influence of Paulo Freire's work seem particularly strong within American adult learning research, although Freire uphold an outlier position in the full space of citations, perhaps due to the fact that he never contributed to the field as such, wrote much of his work a long time ago and in Spanish.
} 


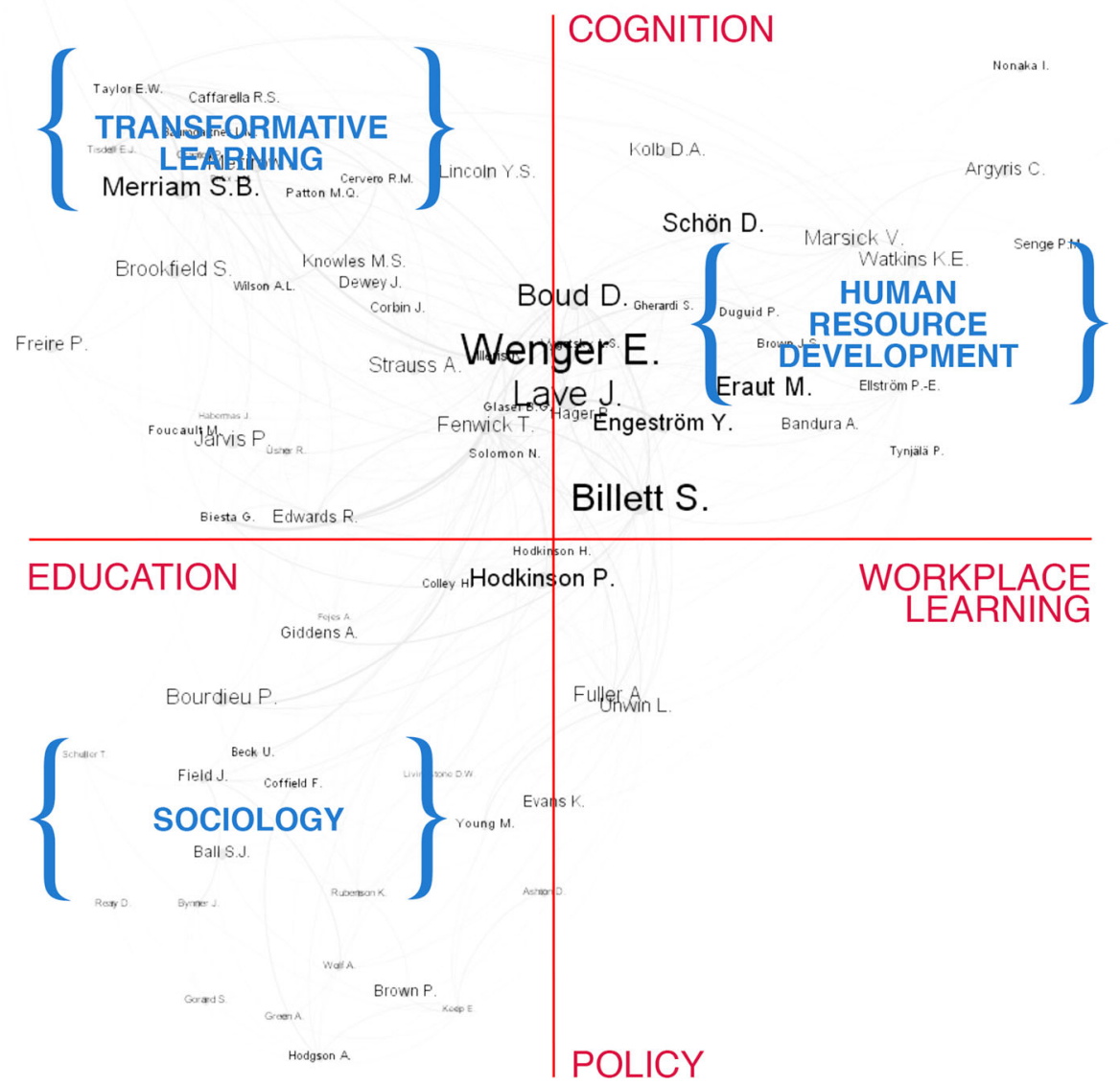

Fig. 2 Structural interpretation of the space of citations in research on adult learning, 2006-2014

Moving from the west to east spans citation bibliographies of authors working with education and educational systems (e.g. Jarvis, Biesta, Brookfield, Edwards, Field, Ball) and bibliographies who primarily study workplace learning (e.g. Schön, Ellström, Eraut, Watkins, Marsick, Unwin). Another perhaps less obvious result discernible from the global map of citations is that bibliographies with more critical perspectives can be found to the west, while more descriptive scholars can be found to the east. The critical impetus on adult learning thus unites otherwise rather diverse scholars such as those working on transformative learning, and those drawing on sociological theory or poststructuralist thought, whereas the more descriptive research tradition seems stronger in workplace learning and among scholars related to human resource development (HRD).

Looking instead at the vertical dimension from south to north, we see how authors wellcited in the south tend to focus on issues pertaining to social structures, policy or transitions from education to work (e.g. Ball, Brown, Evans, Field, Rubenson, Hodkinson), while dominating scholars to the north tend to deal more closely with processes of human cognition and the prospect of transformative learning processes (e.g. Taylor, Kolb, Merriam, Schön, Mezirow). Although these scholars themselves are likely to object, it is tempting to 
interpret this cleavage as one separating more macro-oriented research in the south from researchers who deal with learning as a micro-process in the north.

In the middle of the figure we find bibliographies related to the most dominating tradition within adult learning over the last few decades - sociocultural perspectives on learning (e.g. Lave, Wenger, Billett, Engeström, Boud) as well as what seems to have emerged as a popular research tradition more recently, namely that of practice theory (e.g. Hager, Gherardi, Fenwick). The bibliographies in the middle seem to be citable by authors from both west and east, as well as south and north, thus illustrating the possible generic traits of sociocultural as well as practice theory. ${ }^{12}$

\section{Concluding Remarks: a Bibliographic Field Analysis of Research on Adult Learning}

In the following we will conclude by considering our results in relation to previous studies on the field of adult learning, as well as in relation to our bibliometrical method. Some of our findings relate quite specifically to adult learning as a research field, whereas we also believe that it could be read as a case of how research practices can be studied based on bibliographical and citation data.

In relation to adult learning as a research field our analysis has provided more detailed insights into how "standard references" emerge through citation practices and how individual scholars obtain cogent collegial positions in relation to one another. Although our analysis confirms previous studies as regards to the dominance of anglophone scholars (e.g. Fejes and Nylander 2014, 2017; Larsson 2010) and sociocultural theories (e.g. Fejes and Nylander 2015), we have been able to provide further insight into the relation between dominating players and as well as outlined a structural interpretation of the different epistemic camps active within the field. Broadly conceived one such structural opposition cuts between those researchers primarily studying education or educational systems (e.g. Jarvis, Biesta, Brookfield, Edwards, Field, Ball) and those who primarily study workplace learning (e.g. Ellström, Eraut, Watkins, Marsick, Unwin). The second opposition separates those scholars that are more sociologically oriented and that tend to focus on social structures, policy or transitions from education to work (e.g. Ball, Field, Brown, Evans, Rubenson, Hodkinson) and hose that deal more closely with processes of human cognition and the prospect of transformative learning (e.g. Taylor, Kolb, Merriam, Schön, Mezirow). We also found that most dominating tradition within adult learning in the last few decades sociocultural perspectives on learning (Lave \& Wenger, Billett, Engeström, Boud) and, more recently, practice theory (e.g. Fenwick, Hager, Gherardi, Edwards) - occupy a central mediating position in the space of citations, balancing between the opposing poles of education and work, policy and cognition. We can summarize these findings to five points.

Firstly, by analysing citation patterns in the field between 2006 and 2014, we can see how those bibliographies representing sociocultural theoretical traditions seem to maintain a strong position due to their ability to be rendered citable by scholars from a range of different theoretical domains, scholars interested in analysing educational practices as well as those focusing on learning in the workplace. This might be taken to illustrate the generic qualities of the perspective, i.e. sociocultural theory speaks to a wide audience regardless of what

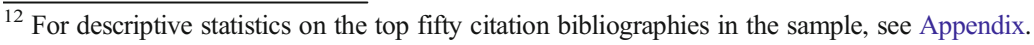


research object is being studied or what objective the particular scholar ultimately has in mind. More crudely put, our results can also be seen as illustrating how sociocultural theory has become the mainstream perspective adopted in the research on adult learning.

Secondly, the centrality of the position occupied by sociocultural theories on learning also seems to build on the perspectives ability to transgress institutional and geographical boundaries, as these scholars have successfully mediated research between scholars located in the US, Europe and Australia. As previous studies have illustrated (e.g. Fejes and Nylander 2014; Larsson 2010), and what our study also seems to confirm, is that there is surprisingly little interaction between scholars located in different continents. With the mediating role of sociocultural theory - simultaneously the most mainstream and generic position within the field - scholars have potentially reached a readership that spans continents and scholastic divides.

Thirdly, the centrality of the bibliographies occupied by scholars from four Anglophone countries - the UK, USA, Canada and Australia and the striking absence of bibliographies of scholars from other countries - illustrate a geopolitical bias in the field in terms of what is picked up and construed as citable. There are many factors that could be raised to help explain such an outcome; not least how English speaking journals have increasingly become those deemed as "international" across the globe (Archambault et al. 2006; Gingras 2016, 54-57). However, and perhaps more surprisingly, biographies of Australian authors are those who become positioned as among the most central ones in our cartography on adult learning (e.g. Billett, Boud, Solomon, Hager). These authors, representing sociocultural as well as practice theoretical traditions, has thus managed to establish themselves as mediators between intellectual traditions and scholars located in different countries. Such position might be explained by their need to be intellectually mobile. That is, by living in a rather sparsely populated country (Australia), there is a need to engage with a wider literature and academic debates than that available in one's own country. Or rather, the academic community of adult learning researchers in Australia could be seen as rather small in comparison to other dominant countries (US, UK), which pushes these scholars to engage with scholars more broadly. In doing so they are, consciously or unconsciously, assigned the role as citable mediators in this diverse and rather pluralistic research field. ${ }^{13}$

Fourthly, by focusing on the full citation bibliographies, we have been able to identify the positions taken by scholars who are editing journals in the field under scrutiny. Although we cannot say anything about the causality between being a gatekeeping editor and attracting citations, we can conclude that editors of journals in the field, to a large extent, are representing key citation bibliographies that are symbolically recognized by other colleagues. Thus one might argue that our results have confirmed that editors are selected as editors due to being centrally positioned in the field or that editors of leading journals tend to gather more citations based on their gatekeeping position.

\footnotetext{
${ }^{13}$ However, please bear in mind that the way we chose to fractionalize citations (see section "Method, Data and Analysis") favours the most productive and collaborative scholars that are being cited in the field. In so far that Australian scholars are producing more collaborative articles that is being picked-up and cited among colleagues, our research method is thus helping translating that graphically into the central area of the space of citations. Another reservation for interpreting the centrality of Australian scholars in the field in terms of scholastic excellence or research quality, has to do with the political steering mechanisms for academic production in which Australia have had a rather extreme policy based on journal publication alone. Butler (2003) has shown how this has resulted in increased publication activity paired with a decline in general impact.
} 
Fifthly, it is important to note how the selection of these specific journals influence the way the field is shaped. Even though the journals have been selected as representative of the wider field of adult learning research, they do themselves have specific profiles through what is published and cited within the journals. Although analysis of each specific journal is outside of the scope of this article, we could note, for example, that the reason for human resource development research emerging as a central cluster in our results is due to us having included the Journal of Workplace learning in our sample. The journal is published in the US, it is dominated by bibliographies of US scholars, and HRD is one key theoretical terrain in workplace learning research in the US. Another example is our selection of the Adult Education Quarterly, which help generate another North American cluster, here around bibliographies of researchers on transformative learning research, and those more influenced by the reception of the Marxist tradition in the US. Without Adult Education Quarterly in our sample, transformative learning theory would not have emerged in our presentation of the results.

\section{Some Notes on Bibliometrics and Suggestions for Future Research}

Our research might also be deemed relevant to scholars outside of the research field of adult learning, in particular bibliometricians and scholars interested in ways to study the fabrication and recognition of knowledge through publications (Gingras 2016; Hicks 2013). By drawing on all citations in the reference list of all articles published in the journals, we have been able to identify the citation bibliographies that are positioned as the most central ones in a specific research field. Usually, such analyses are conducted with a focus only on those publications cited that are indexed in one of the indexing databases. Thus, only journal articles tend to be included. The merit of including more material than the journal articles when measuring and analysing the impact of research within the social sciences is far from a new discovery. For instance, Boyack and Klavans (2014) showed the importance, especially for the social sciences, of including non-source items in science maps. Similar arguments have been made by bibliometricians when comparing different branches of research by means of citation and publication practices (cf. Lariviére et al. 2006; Hicks 2013, 2004; Gingras 2016).

However, we have not come across a similar method as our own operationalized for dissecting the positionality of scholars in a specific scientific subfield. In our study, we have methodically included all kinds of academic publications possible, i.e. everything deemed relevant and cited from a specific author. Thus, we provide knowledge about those citation bibliographies that are most centrally positioned, but which are not necessarily bibliographies shaped through journal publications as such. Such knowledge is important to the field of adult learning (as well as other social sciences fields) where many of the conventional citations are related to publications in other forms than journal articles and external authorities for social science more widely (cf. Budd 1990; Budd and Magnuson 2010; Lariviére et al. 2006).

For future research it would be of interest to include references from other publication types than journal articles in the construction of an author citation network and dig deeper in the kind of symbolic assets the dominating players in the field have at their disposal. One difficulty with extending the analysis to include the citation practices in books and book series is the lack of digitalized data of these publications as compared to Scopus or WoS. It would also be relevant to further trace the transformations of adult 
learning as a research field over time. For instance, why is the corner of the map that orients towards bibliographies engaged in policy analysis and workplace learning so empty? How did sociocultural perspectives come to render such a dominant position within this field? How come most North American scholars' uptake such a distant and relatively peripheral position in the space of citations in relation to European and other English-speaking collages? However, all this is quite a difficult endeavor due to the time it would take to aggregate historical data on the emergence of these citation practices, construct a relational database and perform a rigorous scientific analysis.

\section{Appendix}

Table 1 Table of the fifty most cited authors between the years 2006-2014

\begin{tabular}{|c|c|c|c|}
\hline Author & $\begin{array}{l}\text { Sum of citations } \\
\text { (fractionalized) }\end{array}$ & $\begin{array}{l}\text { Number of published } \\
\text { articles in sample of journals }\end{array}$ & $\begin{array}{l}\text { Country of institutional } \\
\text { affiliation }\end{array}$ \\
\hline Wenger E. & 355 & 0 & USA \\
\hline Billett S. & 343 & 8 & Australia \\
\hline Lave J. & 243 & 0 & USA \\
\hline Engeström Y. & 242 & 0 & Finland \\
\hline Mezirow J. & 241 & 0 & USA \\
\hline Merriam S.B. & 229 & 4 & Great Britain \\
\hline Boud D. & 198 & 7 & Australia \\
\hline Hodkinson P. & 185 & 0 & Great Britain \\
\hline Unwin L. & 182 & 3 & Great Britain \\
\hline Bourdieu P. & 179 & 0 & France \\
\hline Fuller A. & 178 & 2 & Great Britain \\
\hline Freire P. & 174 & 0 & Brazil \\
\hline Eraut M. & 163 & 0 & Great Britain \\
\hline Schön D. & 151 & 0 & USA \\
\hline Fenwick T. & 142 & 7 & Great Britain \\
\hline Edwards R. & 141 & 2 & Great Britain \\
\hline Brookfield S. & 134 & 2 & USA \\
\hline Marsick V. & 133 & 2 & USA \\
\hline Jarvis $\mathrm{P}$. & 133 & 0 & Great Britain \\
\hline Foucault M. & 122 & 0 & France \\
\hline Taylor E.W. & 112 & 5 & USA \\
\hline Brown P. & 112 & 0 & Great Britain \\
\hline Strauss A. & 111 & 0 & USA \\
\hline Watkins K.E. & 104 & 1 & USA \\
\hline Giddens A. & 102 & 0 & Great Britain \\
\hline Dewey J. & 96 & 0 & USA \\
\hline Field J. & 96 & 1 & Great Britain \\
\hline Ball S.J. & 94 & 0 & Great Britain \\
\hline
\end{tabular}


Table 1 (continued)

\begin{tabular}{|c|c|c|c|}
\hline Author & $\begin{array}{l}\text { Sum of citations } \\
\text { (fractionalized) }\end{array}$ & $\begin{array}{l}\text { Number of published } \\
\text { articles in sample of journals }\end{array}$ & $\begin{array}{l}\text { Country of institutional } \\
\text { affiliation }\end{array}$ \\
\hline Biesta G. & 92 & 2 & Great Britain \\
\hline Knowles M.S. & 91 & 0 & USA \\
\hline Gherardi S. & 86 & 1 & Italy \\
\hline Hager P. & 85 & 3 & Australia \\
\hline Tisdell E.J. & 83 & 4 & USA \\
\hline Kolb D.A. & 83 & 0 & USA \\
\hline Argyris C. & 82 & 0 & USA \\
\hline Ellström P-E. & 78 & 4 & Sweden \\
\hline Wilson A.L. & 77 & 1 & USA \\
\hline Young M. & 75 & 3 & Great Britain \\
\hline Usher R. & 74 & 0 & Australia \\
\hline Beck U. & 71 & 0 & Germany \\
\hline Cranton P. & 70 & 2 & USA \\
\hline Cervero R.M. & 69 & 2 & USA \\
\hline Keep E. & 67 & 1 & Great Britain \\
\hline Lincoln Y.S. & 67 & 0 & USA \\
\hline Evans K. & 67 & 1 & Great Britain \\
\hline Solomon N. & 66 & 3 & Australia \\
\hline Bandura A. & 66 & 0 & USA \\
\hline Dirkx J.M. & 60 & 2 & USA \\
\hline Brown J.S. & 59 & 0 & USA \\
\hline Duguid P. & 59 & 0 & USA \\
\hline
\end{tabular}

Open Access This article is distributed under the terms of the Creative Commons Attribution 4.0 International License (http://creativecommons.org/licenses/by/4.0/), which permits unrestricted use, distribution, and reproduction in any medium, provided you give appropriate credit to the original author(s) and the source, provide a link to the Creative Commons license, and indicate if changes were made.

\section{References}

Archambault, É., Vignola-Gagné, É., Côté, G., Larivière, V., \& Gingras, Y. (2006). Benchmarking scientific output in the social sciences and humanities: the limits of existing databases. Scientometrics, 68(3), 329342.

Åström, F., Danell, R., Larsen, B., Schneider, J. (2009). Celebrating scholarly communication studies: a Festschrift for Olle Persson. Published by ISSI. vol. 05-S June 2009. International Society for Scientometrics and Informetrics. http://issi-society.org/ollepersson60/ollepersson60.pdf. Accessed 5 Sept 2016.

Bastian, M., Heymann, S., Jacomy, M. (2009). Gephi: an open source software for exploring and manipulating networks. International AAAI Conference on Weblogs and Social Media.

Bourdieu, P. (1985). The market of symbolic goods. Poetics, 14(1), 13-44.

Bourdieu, P. (1988). Homo Academicus. Cambridge: Polity Press.

Bourdieu, P. (2004). Science of science and reflexivity. Oxford: Polity Press. 
Bourdieu, P., \& Wacquant, L. J. D. (1992). An invitation to reflexive sociology. Chicago: Univ. of Chicago Press.

Boyack, K. W., \& Klavans, R. (2014). Including cited non-source items in a large-scale map of science: what difference does it make? Journal of Informetrics, 8(3), 569-580.

Bright, B. P. (Ed.). (1989). Theory and practice in the study of adult education: the epistemological debate. London: Routledge.

Broady, D. (1991) Sociologi och epistemologi: om Pierre Bourdieus författarskap och den historiska epistemologin. Diss. Stockholm: HLS.

Budd, J. M. (1990). Higher education literature: characteristics of citation patterns. The Journal of Higher Education, 61(1), 84-97.

Budd, J. M., \& Magnuson, L. (2010). Higher education literature revisited: citation patterns examined. Research in Higher Education, 51, 294-304.

Butler, L. (2003). Explaining Australia's increased share of ISI publications - the effects of a funding formula based on publication counts. Research Policy, 32(1), 143-155.

Carruthers, B., \& Espeland, W. N. (1991). Accounting for rationality: double-entry bookkeeping and the rhetoric of economic rationality. The American Journal of Sociology, 97(1), 31-69.

Espeland, W. N., \& Sauder, M. (2007). Rankings and reactivity: how public measures recreate social worlds. American Journal of Sociology, 113(1), 1-40.

Fejes, A., \& Nylander, E. (2014). The Anglophone international(e): a Bibliometrical analysis of three adult education journals, 2005-2012. Adult Education Quarterly, 64(3), 222-239.

Fejes, A., \& Nylander, E. (2015). How pluralistic is the research field on adult education? Dominating bibliometrical trends, 2005-2012. European Journal for Research on the Education and Learning of Adults (RELA), 2015, 103-124.

Fejes A. \& Nylander, E. (2017). Adult education research: publication strategies and collegial recognition. In M. Milana et al (Eds.), Palgrave international handbook on adult and lifelong education and learning, Palgrave. ISBN 978-1-137-55782-7.

Gingras, Y. (2014). Criteria for evaluating indicators. In B. Cronin \& C. R. Sugimoto (Eds.), Beyond Bibliometrics: harnessing multidimensional indicators of scholarly impact (pp. 109-125). Cambridge: MIT Press.

Gingras, Y. (2016). Bibliometrics and research evaluation. Cambridge: MIT Press.

Harris, R., \& Morrison, A. (2011). Through the looking glass: adult education through the lens of the Australian journal of adult learning over fifty years. Australian Journal of Adult Learning, 51, 17-52.

Heilbron, J. (2015). French sociology. Cornell: Cornell University Press.

Hicks, D. (2004). The four literatures of social sciences. In H. Moed, W. Glänzel, \& U. Schmoch (Eds.), The handbook of qualitative science and technology research (pp. 473-496). Dordrecht: Kluwer.

Hicks, D. (2013). One size doesn't fit all: On the co-evolution of national evaluation systems and social science publishing. Confero: Essays on Education, Philosophy and Politics, 1, 67-90.

Käpplinger, B. (2015). Adult education research between field and rhizome: a bibliometrical analysis of conference programs of ESREA. European Journal for Research on the Education and Learning of Adults, 6(2), 139-157.

Karpik, L. (2011). What is the price of a scientific paper? In J. Beckert \& P. Aspers (Eds.), The worth of goods: valuation and pricing in the economy (pp. 63-85). New York: Oxford University Press.

King, J. (1987). A review of bibliometric and other science indicators and their role in research evaluation. Journal of Information Sciences, 13, 261-276.

Lamont, M. (2009). How professors think: inside the curious world of academic judgment. Cambridge: Harvard University Press.

Lariviére, V., Archambault, É., Gingras, Y., \& Vignola-Gagné, É. (2006). The place of serials in referencing practices: comparing natural sciences and engineering with social science and humanities. Journal of American Society for Information Science and Technology, 57(8), 997-1004.

Larsson, S. (2009). An emerging economy of publications and citations. Nordisk Pedagogik, 29, 34-52.

Larsson, S. (2010). Invisible colleges in the adult education research world. European Journal for Research on the Education and Learning of Research, 1(1-2), 97-112.

Nylander, E. (2014a). Mastering the jazz standard. American Journal of Cultural Sociology, 2(1), 66-97.

Nylander, E. (2014b). The rites of jazz institutions: Uncertainty and valuation in music auditions. American Journal of Cultural Sociology., 2(2), 266-276.

Persson, O. (1991). Forskning i bibliometrisk belysning. Umeå: INUM.

Rubenson, K., \& Elfert, M. (2015). Adult education research: exploring an increasingly fragmented map. European Journal for Research on the Education and Learning of Adults, 6(2), 125-138. 
Sapiro, G. (2010) "Introduction" in Sociology is a martial art: political writings by Pierre Bourdieu. New York: New Press.

Small, H. G. (1973). Co-citation in the scientific literature. Journal of the American Society for Intformation Science, 24(4), 265-269.

St.Clair, R. (2011). Writing ourselves into being: A review of the Canadian journal for the study of adult education. Canadian Journal for the Study of Adult Education, 23(2), 27-44.

Taylor, E. (2001). Adult Education Quarterly from 1989-1999: a content analysis of all submissions. Adult Education Quarterly, 51(4), 322-340.

Erik Nylander is a Senior lecturer in Education at Linköping University, Sweden. He has previously contributed to wide range of scientific fields including educational- and cultural sociology as well as bibliometrics and sociology of science.

Lovisa Österlund is a Bibliometrician at the Department for Publishing Infrastructure (PI), Linköping University.

Andreas Fejes is professor and chair of adult education research at Linköping University, Sweden as well as one of the founding editors of the European Journal for Research on the Education and Learning of Adults (www.rela.ep.liu.se). His current research concerns citizenship education within and beyond adult and popular education; Marketization of adult education; and the bibliometrics of adult education research. 